\title{
Erratum to: Verifying and Validating Simulations
}

\author{
Nuno David, Nuno Fachada, and Agostinho C. Rosa
}

\section{Erratum to:}

Chapter 9 in: B. Edmonds, R. Meyer (eds.), Simulating Social Complexity, Understanding Complex Systems, https://doi.org/10.1007/978-3-319-66948-9_9

The original version of this chapter was inadvertently published with an entry omitted in the reference list. The missing reference reads as given below:

Fachada, N., Lopes, V. V., Martins, R. C., \& Rosa, A. C. (2017b). Model-independent comparison of simulation output. Simulation Modelling Practice and Theory, 72, 131-149. doi:10.1016/j.simpat.2016.12.013,

http://www.sciencedirect.com/science/article/pii/S1569190X16302854

The updated online version of this chapter can be found at https://doi.org/10.1007/978-3-319-66948-9_9 